\title{
Lactive activities and the process of milking of first-calf cows using robotic milking
}

\author{
Lenar R. Zagidullin*, Rifat R. Khisamov, Rubin R. Kayumov, Igor V. Lomakin, and Nadezhda M. Kanalina \\ Kazan State Academy of Veterinary Medicine named after N.E. Bauman, 420029 Kazan, Russia
}

\begin{abstract}
Studies have been conducted to assess the lactation productivity of first-calf cows of Kholmogory breed of Tatarstan type using robotic milking systems. The following changes in the amount of milking over the course of 10 months of lactation were observed: during the first month, the cows were milked the least number of times, which was 75, or 2.4 times per day. During the second month, they were milked 86 times ( 2.8 per day). By the 4th month, milking reached a peak of 93 times ( 3 per day). By the 5th month, a decline was observed (by $11 \%$ compared to the 4 th month). The average number of milking times per day was $2.8 \pm 0.05$ times. The amount of milking is closely correlated with milk productivity: twicemilked cows had an average productivity of $15.3 \mathrm{~kg}, 3$ times $-19.0 \mathrm{~kg}$, and 4 times $-27.0 \mathrm{~kg}(\mathrm{r}=0.69)$. The milking robot spent approximately 108 seconds, or $29 \%$ of the time spent in the milking box, on preparation activities, including: udder cleaning, 39 seconds; scanning the position of the utter, 21 seconds; and connecting milking cups, 48 seconds. Lactation took most of the time, namely 251 seconds, or $66 \%$. The peak milk production takes place during the second month of lactation, $681.3 \mathrm{~kg}$. By the third month, a decline was observed by $4.8 \%$, to $648.1 \mathrm{~kg}$. The maximum decrease in milk production by $12.4 \%$ occurred between the 5 th and 6 th month of the tested lactation period.
\end{abstract}

\section{Introduction}

The state program for agricultural industry development considers an increase of the efficiency and competitiveness of products based on the technical and technological modernization of the process. One of the directions of dairy cattle breeding intensification is the introduction of loose housing and a robotic milking system.

The need for the use of robots in agriculture is for a number of reasons:

1. The necessity to improve the efficiency in the agricultural industry. The greatest results were achieved by the use of milking robots. It was learned [1] that the costs reduced 6 times, which is one of the most important advantages of milking robots.

2. The current equipment and machinery used in agriculture are outdated. The introduction of milking robots should be a part of an upgrading process, because there is no point in eliminating the existing lag due to the obsolete and old-fashioned equipment.

3. Personnel risks that are the main constraints for the growth of efficiency in the agricultural industry.

4. Robots that meet strict hygiene and safety standards are able to work 24 hours a day; they also free workers from physically difficult tasks [2].

Robotic milking technology has been introduced and is the most advanced in the world. The introduction of milking robots in Russia has increased the output of domestic animal husbandry to a new level. Despite significant capital intensity, modern technologies solve the problem of reducing costs and improving product quality [3]. The direct costs of producing $100 \mathrm{~kg}$ of milk, excluding depreciation on the milking robots, are lower as compared to those of linear installations by $8.6 \%$, and they are lower as compared to those of the milking halls by $10.3 \%$. The transition to robotic milking systems can reduce the culling of cows by an average of $25 \%$ in the herd. The main essence of this technology is to create the highest possible comfort for cows $[4,5]$.

Currently, the number of milking robots in the world is more than 25,000 . It is predicted to be approximately 60,000 by 2020 . The Russian market of milking robots is growing less rapidly in comparison to the global one. According to estimated forecasts, the average annual growth rate in the immediate future will range from 15 to $25 \%$. Currently, the number of automated milking systems is about 500 units. The main obstacle of broad adoption of automatic milking systems is the cost. The price of a one-box system is about 100-120 thousand Euros.

Robotic milking systems are quite different from traditional milking technologies. The purpose of this work was to study Lactation activity of first-calf cows of domestic selections under robotic milking conditions.

\section{Materials and methods}

A study was conducted in the dairy complex of the Akhmetov farm in the Sabinsky district, Republic of

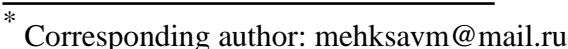


Tatarstan, where 220 Kholmogory breed Tatarstan type cows are kept, including 91 first-calf cows. The complex is divided into 3 sections, 2 of which contain dairy cows. The containment system is box-free. The movement of cows is organized according to the principle of free movement.

The milking of animals is carried out by four one-box robots «Astronaut A4» by «Lely». The cows were fed through multicomponent mixed rations 3 times a day as well as concentrated feed at milking stations. Information about productivity and milking parameters on robots was taken from the Lely T4C herd management information system. The data were analyzed following traditional methods using MS Excel.

\section{Results}

First-calf cows, following the transfer from the birthing section to the general population, had to be trained to use milking boxes. The herd managing program sent signals to operators about the animals which had not reached a milking box for a long time, over 12 hours, as a rule. In such cases, humans helped the animals enter a milking box. To motivate cows to enter the milking boxes, a portion of feeding mix was given to them there. The number of milking times of first-calf cows during a 10-month period was analyzed (Fig. 1).

During the first month of lactation, first-calf cows were milked the minimum number of times, which is 75 \pm 4.5 /month approximately $(\mathrm{CV}=18.3 \%)$ or 2.4 times/day. By the second month, the frequency of milking times increased by $14.6 \%$ and reached $86 \pm 8.2$ times (2.8/day). Then the number further increased and reached its peak by the fourth month of the lactation period, which was $93 \pm 5.7$ times ( 3 times/day; $p<0.05$ ). By the fifth month, a critical decline by $11 \%$ in comparison to the fourth month was observed; then, the number fluctuated between 78 to 85 times/month, with a declining trend by months 9 and 10 .

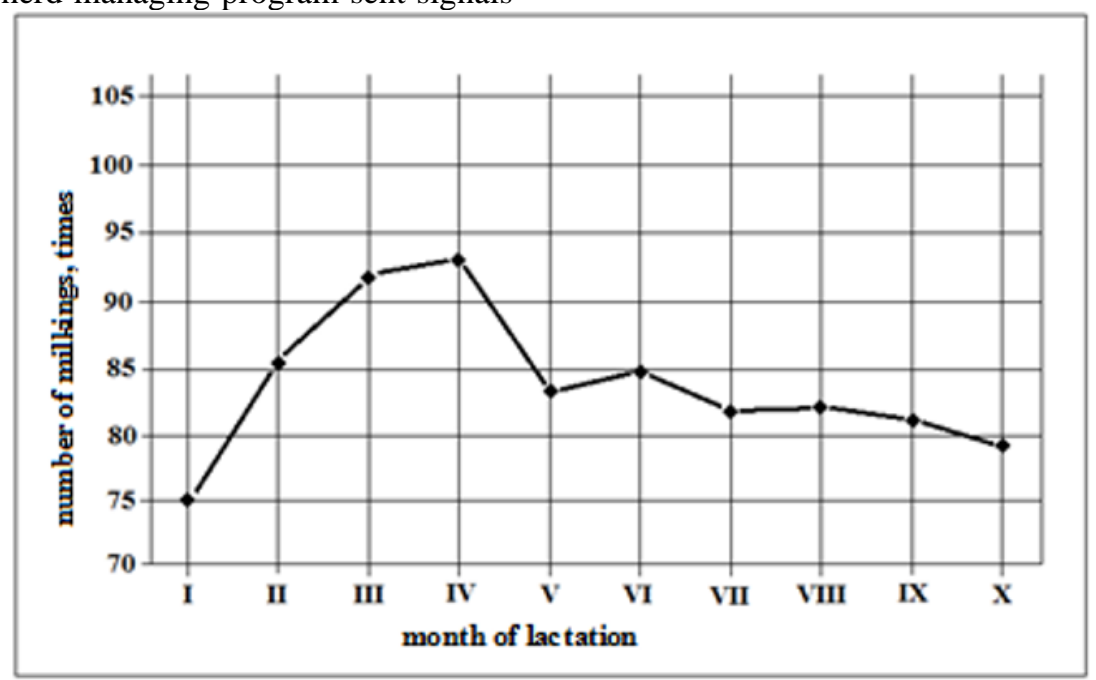

Fig. 1. Number of milking first-calf cows for 10 months

One of the advantages of milking robots was the readiness to perform milking at any time. The minimum time period between milking times or the maximum available number of milking times can be chosen in program settings. At the Achmetov farm, the minimum time between milkings was four hours. So, cows could be milked six times/day. The research showed that the number of milking was $2.8 \pm 0.05$ times/day approximately $(\mathrm{CV}=19.5 \%)$.

Fifty-seven first-calf cows, which is $63 \%$ of the study population, were milked 3 times a day. Twenty cows, which represents $22 \%$ of the population, were milked twice a day; 13 cows, which is $14 \%$, were milked 4 times a day, and 1 cow was milked 5 times a day (Fig. 2).

To find the correlation between the number of milking times and a cow's productivity, we analyzed milk yield with different amounts of milking. The analysis showed that there that there was a direct positive correlation between these indicators: Cows, which were milked twice a day, had approximate productivity $15.3 \pm 0.87 \mathrm{~kg}$, the cows, which were milked 3 times a day, had an approximate productivity of $19.0 \pm 0.41 \mathrm{~kg}(\mathrm{p}<0.01)$. The cows, which were milked 4 times a day, had an approximate productivity of $27.0 \pm$ $1.03 \mathrm{~kg}(\mathrm{p}<0,001)$. The correlation coefficient between the indicators was $r=0.69$ (Fig. 2).

The milking process in the milking box consisted of several successive operations, which were performed by robots. Analysis of the distribution of time for their execution showed (Fig. 3) that the robot spends on average 108 seconds on before-milking activity, or $29 \%$ of the total time, while the optimum preparation time should not exceed 60 seconds. Exceeding this time may be the cause of an inhibition of the lactation reflex.

Thirty-nine seconds from 108 seconds were spent on cleaning of the udders by rolling brushes; the remaining 69 seconds were spent on positioning and scanning (21 s) and connect the test cups to the nipples 48 seconds. The milk stream appeared 18 seconds following connection of the milking cups. Lactation took 251 seconds, or $66 \%$, of the entire total spent in the milking box. So, it took milking robot 377 seconds (6.17 minutes) to perform all the operations $(\mathrm{CV}=50 \%)$. 


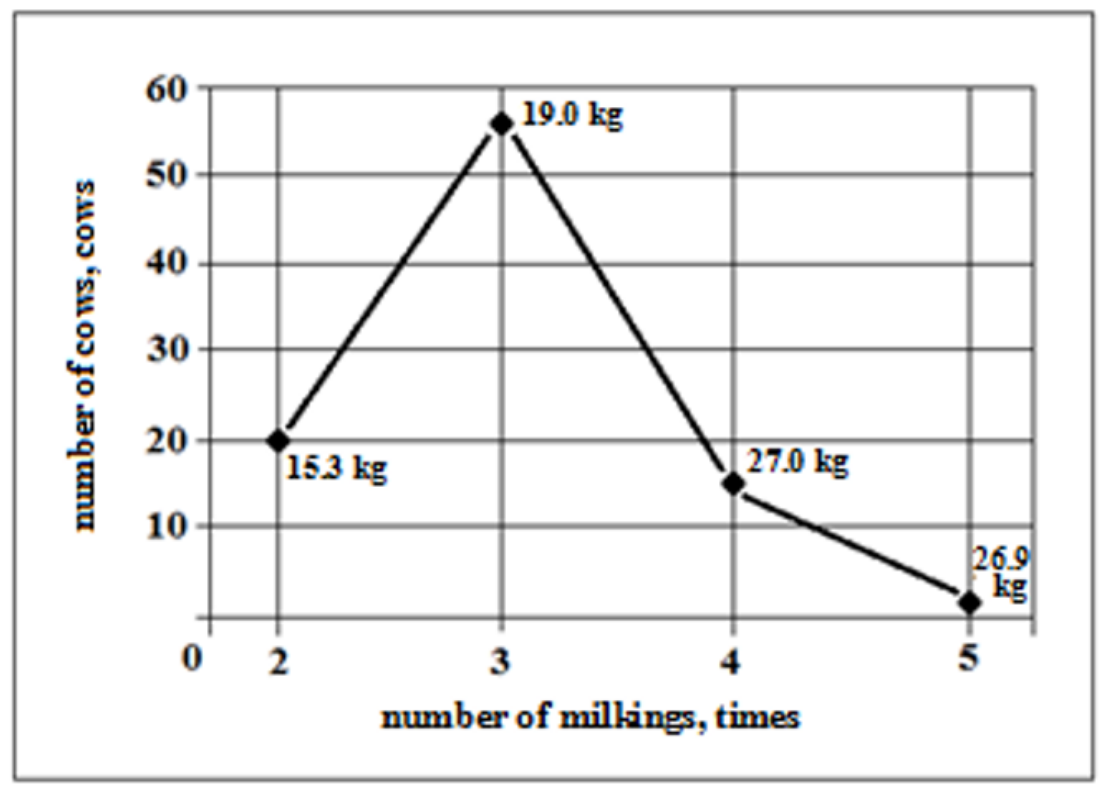

Fig. 2. The distribution of the number of milking cows per day using the milking robot

The set of time cows spent in milking boxes is nonuniform - the coefficient of variation is $51.2 \%$. There were cows that were giving milk less than 4 minutes $(8.8 \%)$ and cows giving milk more than 10 minutes $(15.4 \%)$. The most part of animals $(62.7 \%)$ was in the milking boxes from 4 to 8 minutes.

The connection of dairy efficiency of cows with the time spent in milking box is ambiguous. Extension of time up to 8 minutes is followed by increasing the efficiency. With the further growth of time the nature of interrelation is opposite. Such ambiguity as a result leads to almost zero correlation between indicators $(\mathrm{r}=0.04)$.
The time cows spent in milking boxes depends not so much on time of direct milking $(\mathrm{r}=0.14)$, as on time of processing of udder $(\mathrm{r}=0.84)$. If the processing of udder of cows being in milking boxes within 4-6 minutes is 2.08 minutes, then that for the cows, being there for 6-8 minutes, is 2.41 minutes. The time cows spent in milking boxes depends also on functional features of cow's udders. Negative connection between lactation and the time of milking is obvious. Animals, being in milking boxes less than 4 minutes, had the speed of lactation of $2.16 \mathrm{~kg} / \mathrm{min} ; 8-10$ minutes $-1.41 \mathrm{~kg} / \mathrm{min}$ $(\mathrm{r}=-0.31)($ Table 1$)$.

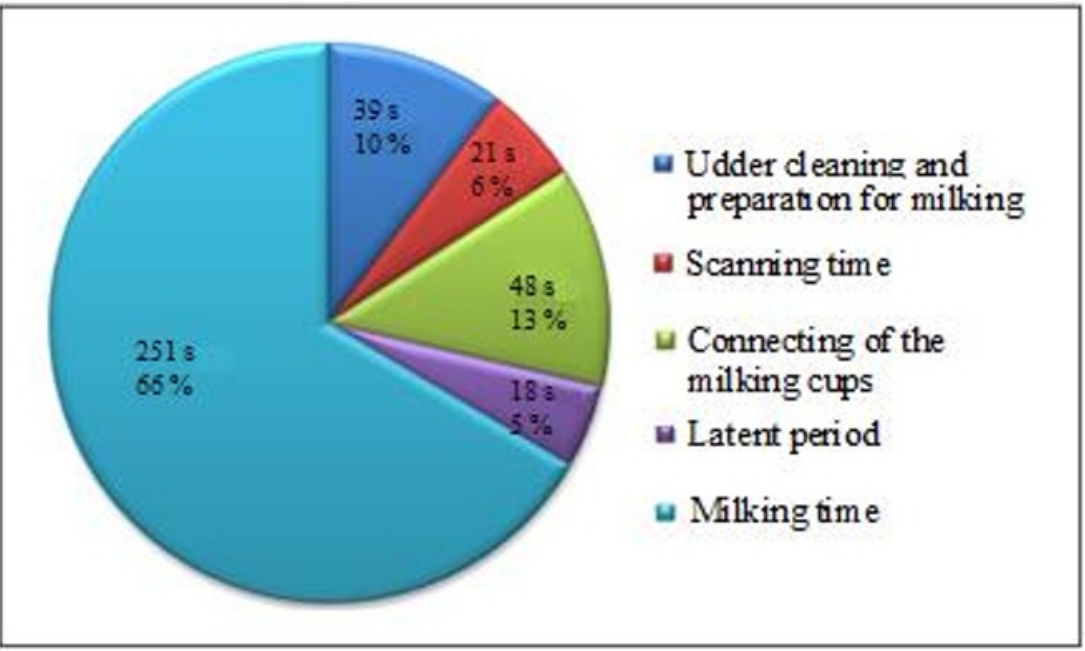

Fig 3. Time distribution to perform individual robot operations

Table 1. Distribution of cows on the time spent in milking boxes

\begin{tabular}{|l|c|c|c|c|c|}
\hline \multirow{2}{*}{ Indicator } & \multicolumn{5}{c|}{ Time spent in milking box, min } \\
\cline { 2 - 6 } & $<4$ & $4-6$ & $6-8$ & $8-10$ & $>10$ \\
\hline Number of cows, cows (\%) & $8(8,8)$ & $28(30,8)$ & $29(31,9)$ & $12(13,1)$ & $14(15,4)$ \\
\hline Daily yield of milk, kg & $15.2 \pm 1.8$ & $18.8 \pm 0.67$ & $21.6 \pm 1.04^{* *}$ & $20.0 \pm 1.10^{*}$ & $18.0 \pm 0.94$ \\
\hline Time of udders' processing, min & $1.31 \pm 0.01$ & $2.08 \pm 0.01^{* * * *}$ & $2.41 \pm 0.01^{* * *}$ & $2.35 \pm 0.01^{* * *}$ & $8.25 \pm 0.06^{* * *}$ \\
\hline Milking time, min & $1.55 \pm 0,01$ & $3.25 \pm 0,01^{* * *}$ & $5.0 \pm 0,01^{* * *}$ & $7.12 \pm 0.01^{* * *}$ & $7.52 \pm 0.03^{* * *}$ \\
\hline Speed of lactation, kg/min & $2.16 \pm 0.13$ & $2.05 \pm 0.13$ & $1.9 \pm 0.11$ & $1.41 \pm 0.10^{* * *}$ & $1.49 \pm 0.16^{* *}$ \\
\hline
\end{tabular}

$* \mathrm{p}<0.05 ; * * \mathrm{p}<0.01 ; * * * \mathrm{p}<0.001$ 


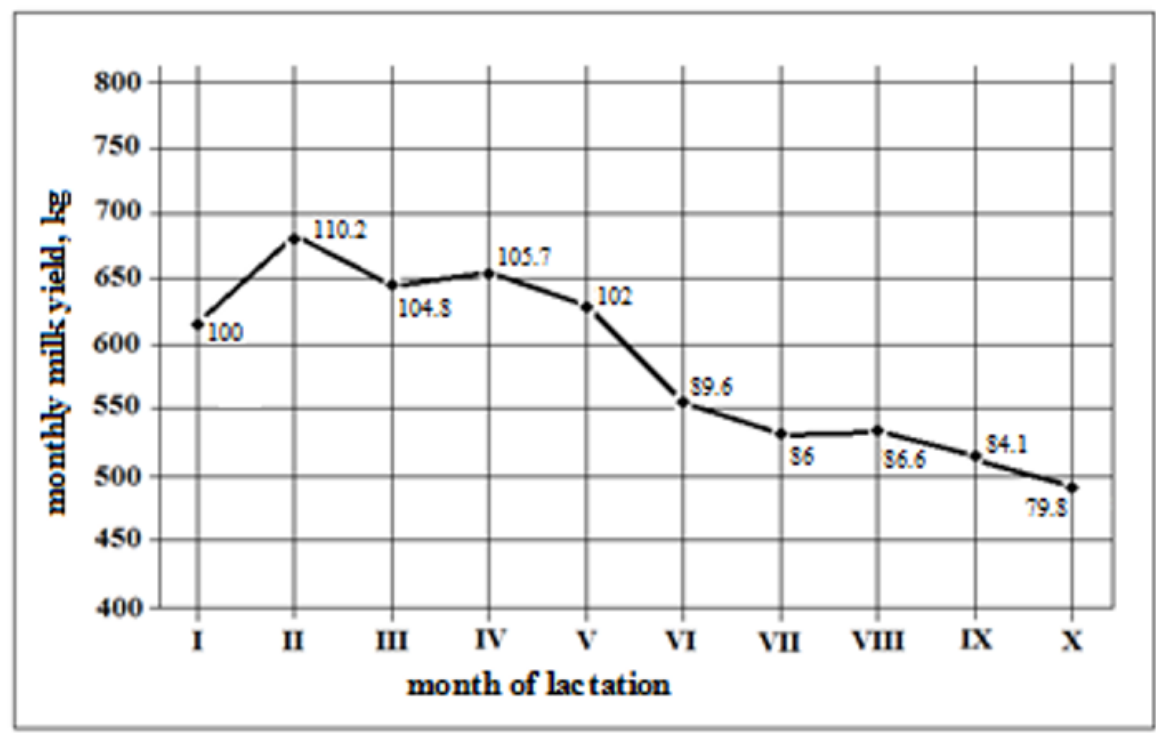

Fig. 4. The line of the figure of lactation period of first-calf cows in the robotic milking system

The line of the figure, which represents lactation of the Kholmogory breed Tatarstan type, first-calf cows in the robotic milking system, shows that a peak of productivity was reached during the second month of the 305 day lactation period observed, and was $681.3 \pm 47.62 \mathrm{~kg}$, which represents a $10.2 \%$ increase of productivity as compared to the first month (Fig. 4). Further, by the third month, it decreased by $4.8 \%$, or $648.1 \pm 47.35 \mathrm{~kg}$.

The first-calf cows' milk productivity decreased irregularly. Slight increases were observed during the fourth and eight months in comparison to the previous ones, by $0.9 \%$ and $0.6 \%$, correspondingly. The maximum decrease in productivity was observed during the six month of lactation, namely by $12.4 \%$. During other months, slight declines of productivity were observed.

The maximum decline in productivity occurred between the fifth and sixth months of the studied lactation period and equaled $12.4 \%$. A slight decline of yield, ranging from 2.5 to $5.4 \%$, was observed during other months. A coefficient of constancy of lactation also indicates and supports the steady nature of lactation, -0.94 .

\section{Discussion}

The work of most researchers in the field of robotic milking $[6,7]$ demonstrated that the number of voluntary milking of cows is directly dependent on their milk production. Our research confirms the same. Based on this, we can conclude that the benefits of robotic milking will be better manifested in highly productive groups.

The number of milking of first-calf cows is at the lowest level during the first month of lactation, the maximum is in 4 months. Peak productivity is reached by the second month of lactation. Thus, these two interrelated indicators reach higher values in different months of lactation. This is probably due to the fact that the process of getting used to the milking robots takes first-calf cows a longer period of time.

Studies have shown that the total time of preparatory operations of Astronaut A4 milking robots by the Lely Company does not fit well based on physiological norms. It seems to take more time than necessary. The elimination of this problem is evidenced by a strict selection process of the animals for the suitability of robotic technologies and the improvement of the robots themselves.

\section{Conclusion}

The number of independent visits of the milking robots by first-calf cows increases till the 4th month of lactation. In the 5th month the sharp slowdown of the indicator is observed. In the following months, values slightly fluctuate with a trend to a decrease at the end of lactation.

The close correlation between dairy efficiency and the number of milking is revealed. The difference in efficiency between the cows which gave milk 2 and 4 times was $76.4 \%$.

The robot needs on average more than 6 minutes to milk one cow. The robot spends $29 \%$ of this time for premilking preparation of the udder. The lactation takes $66 \%$ of the time the cows stay at the milking station.

The time spent in the milking box depends generally on the time of processing of the udder $(r=0.84)$. The maximum dairy efficiency of the first-calf cow is shown in the 2nd month of lactation. Recession of lactation goes unevenly. In the 4th and 8th months an insignificant extension in efficiency, in relation to the last months, is observed.

The maximum drop in the efficiency between adjacent months of lactation is $12.4 \%$, the minimum $2.5 \%$. 


\section{References}

1. Y.G. Ivanova, A.G. Lapkin, J. of VNIIMZH, 3, 188-190 (2013)

2. E.A. Skvortzov, E.G. Skvortzova, J. of VNIIMZH, 1(21), 85-90 (2016)

3. A.V. Malakhov, V.I. Zhiltsov, L.A. Nikitin, Territ. Issues development, 5, 1-15 (2017)
4. V.N. Surovtsev, V.A. Bilkov, Yu.N. Nikulina, Econ and social changes: facts, trends, forecast, 4, 143-150 (2013)

5. E.A. Tyapugin, S.E. Tyapugin, V.K. Uglin, Achievem. of sci. and technol. in agricult., 4, 77-80 (2013)

6. R.R. Khisamov, L.R. Zagidullin, N.A. Safiullin, Dairy and Beef Cattle Breeding, 3, 23-25 (2016)

7. S. Winnicki, T. Kolodziejczyk, R. GlowickaWoloszyn, A. Myczko, B. Musielska, Engineer. for rural develop., 85-88 (2010) 